\title{
Urbanization and climate change: on the path of the construction of sustainable cities
}

\begin{abstract}
The article analyzes the contribution of large cities to climate change in the context of the global energy transition. This requires moving towards a post-fossil era of the economy and society, all of which implies qualitative transformations of these with respect to the natural and human-social environment; and, of course, implies new territorial (urban-rural) sustainable configurations. The characteristics of urbanization processes, present in the megalopolis of Mexico City, are discussed as an expression of the dominant global economic model and their respective socioenvironmental predatory practices. Likewise, the aggravating factors of global warming are studied, which could be reduced from the cities (in this case the city of Mexico and its metropolitan area), and strategies and actions are proposed to reduce the carbon footprint in those cities. It is concluded that, without the restructuring of the megalopolis, it will be impossible to move towards urban sustainability; what is required to go beyond mitigation and adaptation actions in facing climate change.
\end{abstract}

Volume 4 Issue I - 2019

\author{
Guillermo Torres Carral \\ Doctor in Agricultural Sciences, Department of Rural Sociology, \\ Autonomous University Chapingo, Mexico
}

\author{
Correspondence: Doctor in Agricultural Sciences, \\ Department of Rural Sociology, Autonomous University \\ Chapingo, Mexico, Tel 0159595 21625, \\ Email gatocarr@hotmail.com
}

Received: January 02, 2019 | Published: February 08, 2019

Keywords: climate change, peripheral mega-cities, carbon footprint, urban resilience, sustainable cities

\section{Introduction}

The objective of this article is to discuss how large cities contribute so much to the present climate crisis, but also to their required containment, ${ }^{1}$ taking as an example the Metropolitan Zone of the Valley of Mexico (MZVM); it is suggested that a redesign of those, especially in the world periphery, can contribute to reduce the most serious impacts of this global-local phenomenon; which are measured through the carbon footprint. This arises in the framework of the transition towards the generalized application of renewable energies; against the use and abuse that has been made of fossil fuels. This energy transition is just one more of the great transformations realized in the ways of life and production, in order to overcome socio environmental disaster. The methodology used highlights the following considerations: firstly, we identify the global problem of climate change in the path of the energy transition and in the context of required civilization changes. Next, we discuss the social factors that affect this situation from the point of view of the large cities (mainly peripheral); highly exposed to dramatic socio-environmental impacts, which are aggravated by the course of the current global economic development model. Later, the aggravating factors are raised, as well as the possibilities that large cities have (in this case, the MZVM) in order to help counteract such disturbances; ${ }^{2}$ and finally, we propose the need to move towards ecosocial proposals of urban resilience through an alternative urban-rural territorial model with sustainability.

\section{Energy transition and civilizational changes}

The starting point to address the problems generated by climate change, is the evidence of the correlation between the concentration of greenhouse gases (GHG) and the increase in global temperature

${ }^{1}$ The first consists of greater exposure and vulnerability of the land, representing a point of inflection in society, the second is an opportunity to initiate the required transformations.

2"How can cities adapt to the changes that will come? How can they indicate a future of another kind, a future with low carbon emissions?" Graizbord, B and F Montero, 2011:9.
(UNFCCC, 1998), ${ }^{3}$ which is the product of the high level of consumption of fossil energy, the melting of the poles, deforestation and the dramatic reduction of glaciers, mainly; but also as a result of the corresponding social model, together with and excessive urban growth. In addition, the relationship between climatic changes and those occurring in the axis of rotation of the earth around the sun must be taken into account; ${ }^{4}$ factors all that interact with each other. The atmosphere is a common good $^{1}$ whose state affects everyone, for better or worse. However, the technical and social organization is unsustainable, since it does not facilitate the accumulated gaseous waste (besides liquids and solids) being absorbed by the Earth. This, due to lack of knowledge and of appropriate technologies that would allow accelerating the degradation process and increases the recycling capacity in proportion to the total product. $^{2}$

In addition to the above, the space that Gaia needs for its selfregulation and at the same time, the carrying capacity of the biosphere is reduced. ${ }^{3,4}$ Hence the importance of a territorial ecological order. We must add the most disturbing impacts of global warming, such as the increase in sea level, erratic rainfall and greater soil erosion, global and regional redistribution of flora and fauna, as well as their respective effects on the resurgence of diseases such as malaria, dengue and yellow fever; besides the human disasters articulated with the natural phenomena (mainly floods, and droughts); being their social causes obviously obvious (lack of planning, social inequality, poverty and marginalization). While in the cities the effects of climate change have been, along with the excessive increase in temperature: water scarcity, loss of green areas, pollution, diseases, greater social inequality, as well as economic losses. However, ${ }^{1}$ climate change has accompanied man in all historical stages. In parallel, it is estimated that some positive impacts will also be present, concerning higher productivity of the land in some places such as Europe and America,

${ }^{3}$ Convention on Climate Change (UNFCCC), Kyoto Protocol, United Nations Organization, article 5 , paragraph 3 , page 18 .

${ }^{4}$ Three aspects influence the amount and distribution of solar radiation on the surface of the earth: eccentricity of the orbit, obliquity and precession, see Berger A. (1980: 103-122). 
mainly.

\section{From the city to the megalópolis}

Adiagnosis and analysis of the changes that have occurred in the last decades in Mexico City and its metropolitan area (MZVM) ${ }^{6}$ indicates that its territory has been crossed by the transition of an urbanization pattern characterized by a center and its respective rural periphery, located regionally, towards the configuration of a polycentric and diffuse city, ${ }^{6}$ including a multivariate rural sector increasingly distant and complex (regionally, nationally and internationally). And while globalization has strengthened it, it has also encouraged its extensive growth. It is then a city of cities: the megalopolis of Mexico City; that territorially constitutes much more of the space jurisdiction that was designated as Federal District, which is only a part of it, including its metropolitan area. Thus, the growth of the urban sprawl covers 84 municipalities of the state of Mexico, covering a sixth of the national population concentrated in less than $1 \%$ of territory.$^{7}$ In retrospect, Mexico City has become a simple copy of the megalopolises (like other large peripheral cities) of the rich countries, although immersed in a dynamic that expresses a syncretism of the most diverse forms of urban life, culture and production (and urban-rural relationships too); all this in the framework of enormous regional imbalances and the exacerbated centralization of the national life in which it is inserted.

In the same way, the budgetary resources received to sustain the high subsidies of the city, in fact, have meant real taxes that the entire country must pay to the center. And this will not change as long as the current model persists, which has as its heart the hyper urbanization and centralization. In this scenario, the causes of serious eco-social conflicts grow and reinforce each other. ${ }^{8}$ Consequently, continuing to promote the current urbanization model, in practice, results in the impossibility of sustaining oneself; so, when talking about the urban sustainability of the MZVM, one is necessarily thinking of a renewed city, one that is reborn from it, already in socio-environmental decline (and although it is still very profitable, although generating enormous negative externalities): "All this at the expense of the vertiginous and disorganized transformation of the natural environment, without considering the characteristics of the Basin of Mexico, the rhythms of recovery of natural resources and the energy flows necessary to maintain human settlements of such magnitude; this city is a great consumer of inputs and energy that insists on subsisting under a totally unsustainable logic." 10

And all the above together with the confrontation and competition between the DF (now with the official denomination of Mexico City) and the state of Mexico). Therefore, printing sustainability principles to the MZVM implies that a planned city is less expensive-in the long run-than reinforcing the megalopolis, which of course requires restructuring, since the prevailing anarchy leads to the squandering of resources economic employees.

It is understandable then that the described process carried out in

5"According to projections, crop productivity will increase slightly in medium to high latitudes for temperature increases of up to 1 to $3^{\circ} \mathrm{C}$ depending on the type of crop" (UNEP, 2008:32).

${ }^{6}$ The megalopolis (Mexico city and municipalities of the State of Mexico) represents almost a quarter of the national GDP. ${ }^{9}$

${ }^{7} \mathrm{~A}$ more current definition of sustainability involves considering five dimensions: material, economic, life, social and spiritual. ${ }^{10}$

There are 4 fundamental aspects to achieve urban sustainability: green areas, food, energy efficiency and waste cycle. the city-region of the Valley of Mexico ${ }^{7}$ has been a great destroyer of ecosystems, communities and people. This has resulted in its growing contribution (quantitative and qualitative) to climate warming, due notably to the high atmospheric emissions of waste (GHG and suspended particles) derived from economic and human activities in general. All this as a reflection of the type of urban development realized in recent decades; whereas, regionally, it has meant the temperature rise $^{11}$ about its periphery and surrounding rural cities (intermediate and small). This is largely explained by the agglomeration of buildings and vehicles that implies a greater refractive capacity of sunlight, which in itself causes a rise in the temperature in the cities, decreasing the planetary capacity to reflect and dissipate the solar radiations, mainly the ultraviolet rays (causing phenomena of islands, waves of heat, as well as---rain); This implies that $\mathrm{CO} 2$ emissions are not offset by carbon fixation. All this should be counteracted by the restoration and induction of new green areas (biomass) and surface bodies of water (as well as restitution of aquifers), but also through an urbanization based on clean energies, the use of recyclable and resistant materials (reducing drastically GHG), as well as applying the techniques of nature, drastically reducing their carbon footprint; and above all, more energy efficient and less aggressive towards natural ecosystems. The foregoing turns out to be an expression of the fact that, the city planning attempts put in place, have responded more to the interests of urban capital (financial, real estate, industrial, commercial and services), than to its inhabitants (reducing small residential areas). In addition, transport routes have been established mainly from the interest of real estate projects, regardless of considerations in terms of infrastructure, sources of employment and services. To this we must add the still extreme centralism and its concomitant amount of undesirable impacts, as irreversible.

\section{The catastrophe that threaten us}

As has gestated and reproduced over time, we must accept that the urbanization process of the MZMC represents a great fragility and socio - environmental vulnerability, is so far the equivalent potential literally ticking time bomb $^{8}$ socio-environmental, since the accumulation of the bio-psycho-social factors of environmental damage, has resulted in a permanently organized chaos, and in the context of the submission of the population to power. And to that add climate change and the persistent urban disasters (and the politicaladministrative disarray), as well as the natural ones that it entails, which makes the current situation and the perspective towards increasing the vulnerability and fragility of Mexico City much more complicated ${ }^{12}$ evidenced in the earthquakes of 2017. However, more than waiting for a final catastrophe, the fate of the megalopolis implies the continuity of partial catastrophes (floods, fires, landslides, earthquakes, collapse of the drainage network and the management of garbage, etc.). Thus, the growth of the MZVM is marked by persistent human and ecosystemic degradation and by the threat of environmental governability derived from growing social conflicts. Therefore, to try to sustain an urban conglomerate like this turns out to be quite a contradiction with respect to the health of the planet, the contributions of science, as well as common sense (which in this case is coincident). This is because, the greater the city's growth, it is observed that a greater deployment of eco-social discomforts is proportionally generated, not only in the MZVM but throughout the country. Hence, adaptation and

${ }^{8}$ The megalopolis of Mexico City "may be the prelude to a great ecological catastrophe that in the future will lead, for some, to the forced decentralization of the basin and, for others, the environmental problem must be resolved through technological development"; 12 Ward7 calls it "an ecological Hiroshima". 
mitigation against climate change will be insufficient, which is why true structural changes in the city are required.

\section{Cities and public policies to combat climate change}

According to the purpose of this research, it is of great interest to know how cities can help mitigate climate changes. This is crucial, mainly due to the fact that cities generate 40 to $80 \%$ of global emissions of greenhouse gasses..$^{13}$ Therefore, the really important problem is to combat the warming of the Earth from the urban sphere. The climate has changed irreversibly in recent decades, at the same time that its determining factors have deepened. Therefore, the best way to counteract this fact is not to remain in the mere adaptation and mitigation, presents in the institutional discourse, since they are limited. Therefore, it is necessary to review the environmental policy agenda proposed in the UNFCCC and to propose more appropriate measures in the fight against climate change. These policies outlined in the Kyoto Protocol ${ }^{9}, 14$ and confirmed at the World Summits on Climate Change culminate in the Paris Agreement, ${ }^{11}$ negotiated at the XXI Conference on climate change and signed by 195 countries.

It is important to highlight Article 2 of the Agreement, which sets as its central objective: "Strengthen the global response to the threat of climate change in the context of sustainable development and efforts to eradicate poverty." Here it must be noted that, nevertheless, poverty continues to increase despite all the practical efforts made by different countries to achieve sustainable development. And there is no causal relationship between poverty and environmental destruction, rather both are a consequence of the dominant economic model; so it is very simple to venture that syllogism since social inequality is not talked about, while the presence of poverty is concentrated in the big cities (in Mexico it reaches two thirds of the total urban poverty).$^{15}$ In addition, the three basic objectives of the Paris Agreement consist of:

A. Maintaining the increase of the global average temperature well below $2^{\circ} \mathrm{C}$ with respect to the pre-industrial levels and continuing efforts to limit this temperature increase to $1.5^{\circ} \mathrm{C}$ with respect to pre-industrial levels, recognizing that this would considerably reduce the risks and effects of climate change.

B. Increase the ability to adapt to the adverse effects of climate change and promote resilience to climate and development with low GHG emissions, from a model that does not compromise food production.

C. Increase financial flows to a level compatible with a trajectory that leads to a climate-resilient development with low GHG emissions.

However, the purpose of limiting the increase in global average temperature, this cannot be fulfilled through the announced means since the reduction of GHGs is not a purely technical matter (such as buying new cars less polluting for example) but requires of structural transformations (to limit the private automobile, urban

${ }^{9}$ The Kyoto Protocol proposed reducing GHG by 5\% in 2008-2012 compared to 1990 emissions; expires in the year 2020

${ }^{10} \mathrm{Highlighting}$ those made in 1997 (Kyoto), 2002 (Johannesburg, 2007 (Bali), Copenhagen (2009), Cancun (2020 and Durban (2011).

${ }^{11}$ Paris Agreement (2015), www.unfcc.int/files/meetings/paris.pdf ., Pages 4-8. Thus, even with these adaptation and mitigation measures, the Brazilian megapolis and Santiago de Chile do not stop their urbanization rate. See: "The Brazilian megalopolis", Wójstowicz A. (2017), Uniwersytet Warszawski, Warsaw, page 2 and Welz, and K. Krellenberg (2016), "Vulnerabilities to climate change, case Metropolitan Region of Santiago. Eure, Santiago, vol.42, $\mathrm{n}^{\circ} 125$, January 2016, page 2. deconcentration) in the form of development of the cities as well as in the prevailing urban rationality ${ }^{16}$ So mitigation and adaptation measures are not enough. The first, which involves reducing GHG emissions, imposes a low carbon economy. The second involves facing vulnerabilities (increasing urban resilience); which requires compatibility between the economy and natural cycles. However, it must be recognized that the preventive planning of cities must be exercised; and respecting the natural and sociocultural conditions, as well as the essential rules to achieve a territorial order and, therefore, population.

\section{However, it must be recognized that:}

"There is a high degree of confidence that neither adaptation nor mitigation will be able to avoid, on their own, all the impacts of climate change; they can, however, complement each other and, together, significantly reduce the risks of climate change. ${ }^{17}$ Therefore, it is worth mentioning several strategic lines in this direction beyond mitigation ${ }^{12}$ and adaptation: ${ }^{13}$

1. A just and appropriate relationship between the population and the territory, which implies a real national decentralization;

2. Reconstruction of large cities through a network of green cities with low carbon footprint;

3. Deconcentration of budget resources in agriculture to favor small and medium production units, as well as employment and food sovereignty;

4. Promotion of technological innovation and connectivity based on the eco-social conditions of the country; and Change the model based on insufficient wages and technological backwardness, through a national agreement to improve wages and productivity, strengthening the domestic market.

And in terms of urban resilience (objective c), we must consider: traditional values, conservation of green areas and agroecosystems, community cohesion, environmental education, and so on.

\section{The combat to global warming in Mexico City}

"The future of humanity is in the hands of cities, of urban administrations conscious of their responsibility and of a sustainable urban evolution." 14 Finally, all of the above implies the application of longer-term measures ${ }^{3}$ how to correctly administer the hydrological cycle, counteract the acidification of the seas, increase carbon capture; also, the extension and intensity of biomass production; increasing the capacity to renew renewable natural resources and reducing the use of non-renewable resources $;{ }^{18}$ lessening

\footnotetext{
12"Mitigation means implementing policies to reduce greenhouse gas emissions and enhance carbon sinks" Organization for economic cooperation and development (OECD), ${ }^{19}$ Cities and climate change, OECD publishing, www.oecd-library.org, page 33.

${ }^{13}$ The Intergovernmental Panel on Climate Change defines adaptation as "initiatives and measures to reduce the vulnerability of natural and human systems against current or expected climate change effects". (Houghjton and Din, 2001: 64).

14"Cities represent the battlefield on which the struggle for the future of all mankind will be waged (...)" This (climate change) will require adaptations as to how cities are administered in order to ensure that maintain adequate living standards and continue to attract the investments and human resources necessary to support sustainable development. ${ }^{20}$ However, the future of humanity lies, rather, in a balance between the countryside and the city. The field cannot continue to be the extractive market of the city and even less its landfill.
} 
the aggressiveness of cities and megalopolis (greener, less gray); and promoting the new agriculture aimed at reducing the use of petroleum derivatives and other fossil fuels, through agro ecological, low carbon alternatives. But, the solution is not (only), the energy transition, but to take firm steps towards a deep restructuring of the economy, society and culture. Since there is also to be taken into account that the clean energies that are promoted, are also mostly social pollutants or not appropriate (hydroelectric, wind, nuclear, biofuels). Therefore, the axis is a low carbon economy. Thus, the climate crisis should enable a more rapid environmental transition, since, otherwise, it would continue to be embroidered only on the side effects (atmospheric emissions); without taking into account its foundation: the current economic and life model. The cities are an example of this double aspect mentioned above: that is to accelerate or instead to slow down atmospheric upheavals, for which reason only a few reflections and proposals aimed at their socio-productive restructuring are made here; given that the socio-environmental (and even more civilizatory) problems, although currently manifested in climate change, have other equally worrisome expressions (loss of biodiversity and deforestation, rupture of the water cycle, lack of control of solid and liquid waste, thinning of the ozone layer, etc.), since the environmental crisis is wider than the climate problem. However, it is currently when this issue appears as central, since the climate crisis represents the current phase of the former. ${ }^{15}$

Here the cities are situated as part of the crossroads that arises as a consequence of an economy of high entropy and carbon footprint, which suggests continuing with the predatory mode of nature and humanity or finding alternative solutions from the majorities ${ }^{22}$ and that are viable and feasible, facing the enormous planetary devastation; constituting therefore the historic dilemma of humanity nowadays. In sum: in the context of urban disorganization in progress, it is necessary to consider the participation of large cities (specifically the peripheral cities) to fighting the current serious climate change, characterized by the persistent rise in the average temperature of the atmosphere and the oceans, in a more and more extreme and fluctuating form (drastically modifying the rainfall regime and cloud cover), which occurs independently of natural cycles. This is related to the greater exposure to solar radiation (as well as greater solar radiation), caused by the concentration of GHG generated by the economic model, which has resulted in the increase of the greenhouse effect on planet Earth, due to the higher concentration of heat on the earth's surface; becoming one in an increasingly fragile system, affecting its "sensitivity". ${ }^{23,24}$ Furthermore, the city is becoming a cauldron, which refers not only to atmospheric warming but also to other types of impacts present in the megalopolis in general.

In this way, the following questions can be formulated: can current cities be transformed into low carbon urban conglomerates? ${ }^{16}$ and also: are the institutional proposals for urban sustainability sufficient in face of the magnitude of the vulnerability of megacities? Therefore: "It is not cities, or urbanization per se, that contribute to greenhouse gas emissions, but rather the way in which people move around the city, sprawling urban development, the amount of energy used at home and to heat buildings that make cities the great consumers of energy and polluters that they are "(...)" urban policies can lead to a

${ }^{15}$ The global environmental crisis has gone through several stages: from the fight against pollution in the late sixties of the last century, and then to relate it to biodiversity, water; until now, with the topic of climate change, which encompasses all these problems, see Callicot JB. ${ }^{21}$

${ }^{16}$ The low carbon economy is the option to face climate change ${ }^{19}$ reduction of total OECD global energy demand, consequently, of CO2 emissions at relatively low cost". ${ }^{19}$

\section{Strategic lines of restructuring towards urban sustainability}

At the local level, and as part of the national and global transformations to face climate change), the necessary strategic lines towards the construction of an alternative model means achieving greater restructuring with less vulnerability and greater resilience urban as opposed to the city's destructuring, as part of the technical, socioproductive and energetic transformations that are at the door. These should take into consideration the following aspects:

1. Modify the population / territory relationship, achieving an adequate distribution between these two factors (territorial / population ordering) and promoting the relocation of people and relocation of industries (voluntarily and induced, not compulsive) ${ }^{17}$ all this under the brake to the expansion of the urban sprawl, but generating more jobs.

2. This must be done by respecting and rescuing ecosystems, such as forests, plains and lake areas, channels, dams, rivers, springs, etc. All of which supposes the ecological ordering of the territory.

3. Consequently, it is essential to expand, rescue and intercalate green areas (and bodies of water), establish ecological and agricultural cords and reduce cement spaces in the service of the automobile. It is very important to solve the water crisis and the balance in the recharge of the aquifer; hence, the need to counteract source contamination, overexploitation of the basin and poor wastewater management must be taken into account.

4. In this sense, it is fundamental to understand that the decompression of the city is not incompatible with a compact and intensive urbanization, but flexible, since overcrowding of people is a source of serious individual, family and social tensions.

5. Likewise, an urban reordering (employment, housing, transport, services) requires flexible planning, which is preventive, not reactive.

6. At this point it is very important to bear in mind that the outsourcing of the city, ${ }^{26}$ must be organically connected to a new type of industrialization and the realization of a sustainable city, which does not exclude improving the rural development of the city-region.

7. Obviously, everything pointed out requires the rationalization of subsidies, limiting their political perversion.

\section{Conclusion}

Climate change or global warming: both are expressions of drastic environmental transformations with serious consequences for society and the world, as a result of the energy-civilizing paradigm that ultimately generates climate change - in what corresponds to the human being. Faced with the disagreements in this transcendental topic, it can be said that the only possible consensus, because "The scientific evidence on the warming of the climate system is unequivocal" 3 meaning that we are facing as specie a planetary disaster (and human, obviously). Unfortunately, at the Cancún Summit ${ }^{26}$ COP 16, and other global climate summits, culminating in the Paris Agreements, ${ }^{27}$ the results reached cannot be considered consistent or sufficient (less

${ }^{17}$ Expropriations are established in the Constitution of the United Mexican States for reasons of public utility (Article 27). 
binding).$^{18}$ However, the world can take advantage of climate change, as this is a catalyst for major and necessary changes in society, which indicate that the energetic-technological transition is not enough, but that a change is required above all through drastic changes in the model of life and mentality; that are the anchor of the civilization in motion.

In this way, although the natural causes of these disturbances cannot be modified, ${ }^{5}$ their social causes can be corrected. However, institutional and civil society actions will have to face both aspects; what it means to make more fundamental changes. The transition to a new city is finally the key that allows us to understand that there are solutions to climate change; and these have to do with substantial changes in the base of society.

The task in the way of the construction of sustainable cities imposes three transcendental urban guidelines, from the standpoint of sustaining the bases of the cycle that unites the urban economy with ecosystems:

a) the defragmentation (integrity) of ecosystems natural (and agroecosystems);

b) the intercalation, extension and rescue of green and rural areas; and

c) decompress the megacity city-planning (architecture of the landscape, habitability, fix limits to the population).

Hence the importance of the space-time approach. ${ }^{28}$ Otherwise, just compacting and moving from a horizontal city to a vertical one, would be erroneous because it is insufficient and therefore would result in a social failure with a high cost, and low environmental and life quality of its inhabitants. It is decisive then to move towards the construction of a network of eco-cities for the case of the MZMV territory (planning the construction of housing, transport, services and infrastructure based on renewable and clean energy); promote the eco-technology revolution and sociourban reconstruction; territorial compaction, but slowing the urban sprawl and respecting the non-urbanized and green areas; promoting a development that is compatible (naturally and socially). Here, financing ${ }^{19}$ appears as a decisive issue to make city design a viable and feasible reality. And also take advantage of training, technical assistance and advice in the design and implementation of sustainable development programs. ${ }^{20}$ It can be concluded that, in the face of climate change, a large reconstructive task of large cities (and of urban-rural relations) is required, which allows going beyond mere adaptation and mitigation. In sum, the following paradox can

${ }^{18}$ As voluntary GHG reductions, it initiated the program to Reduce Emissions from Deforestation and Degradation (REDD+), Green Fund (100 billion dollars up to 2020 for developing countries affected by climate change) and technology transfer to developing countries, were the most important. (Agreements of the Cancun Summit, 2010, COP 16).

19 "Measures to reduce greenhouse gas emissions and adapt to expected climate change will have additional pressure on city budgets and increase the need fo additional public resource". In addition, the Habitat II agreements establish that "The Habitat Program will require concerted action on issues such as development financing, external debt, international trade and technology transfer".

${ }^{20}$ See the International Council for Local Environmental Initiatives (ICLEI)Local Governments for Sustainability, ${ }^{9}$ founded in 1996, is the international environmental agency that supports local governments through training, technical assistance and design assistance and implementation of sustainable development programs. Also, the group of 40 cities (C40) is a global network of megacities that take common actions to reduce GHG emissions, assess risks and impacts. be posed: Well climate change is irreversible; its (human) causes are reversible. That is, it is possible to restructure the city, stopping the red hot spots of the local-global disaster, discouraging and reducing its physical and population expansion. And, in fact, the eco-social limits of the city indicate this. ${ }^{29}$

And also, increasing the quality of life of its inhabitants and recovering the resilience capacity of human activities in the city, without reaching the point of supposing that, as megaconcentration is already a fact, it should not and can be reversed. Such capacity presupposes that the drastic transformations to occur must not affect people, communities and ecosystems. All of which indicates that tracing the environmental problem in the MZVM, should not ignore the indispensable social cohesion (with all the interpersonal communication, group, community, political, intercultural and institutional that implies) of its inhabitants. Finally, only a change in the city model, based on territorial and population planning, will really help to combat climate change, which is based on socio-environmental urban degradation in the face of the process of desertification (humannatural) that impacts beyond the city-region. ${ }^{30-38}$

\section{Acknowledgments}

None.

\section{Conflicts of interest}

Author declares that there is no conflicts of interest.

\section{References}

1. Ostrom E. El gobierno de los bienes comunes. México: FCE; 2000

2. Rifkin J, T Howard. Entropía. Hacia un mundo invernadero. Barcelona: Urano; 1993.

3. Houghton J, Y Ding. IPCC. Climate change 2001: the scientific basis. Cambridge: Cambridge University Press; 2001.

4. Stern N. The economics of climate change. American Economic Review. 2007;88(2):1-37.

5. Acot P. Historia del clima. Desde el Bing Bang hasta el calentamiento global. El Ateneo, Buenos Aires; 2005.

6. Aguilar A. Procesos metropolitanos y grandes ciudades, Instituto de Geografia, Centro Regional de Investigaciones Multidisciplinarias/ PUEC/UNAM/Miguel Ángel Porrúa/ Cámara de Diputados. México: LIX legislatura; 2003.

7. Ward P. México megaciudad: desarrollo y política, 1970-2002. EURE (Santiago). 2004

8. Harvey D. Urbanismo y desigualdad social. México: Siglo XXI; 1977.

9. International Council for local environmental initiatives-local governments for sustainability. ICLEI. 2013.

10. Ben Eli M. Sustainability: definition and five core principles. A new framework. New York: The sustainability Laboratory; 2015.

11. Muro P. Cambio climático en la subregión de Texcoco. México: UACh; 2010

12. Ezcurra E, M Mazari, I Pisanty, et al. La Cuenca de México. Aspectos ambientales críticos y sustentabilidad. México: FCE; 2006.

13. Organización de Naciones Unidas, Acuerdos Hábitat II. La declaración de Estambul (1996). 2013.

14. Protocolo de Kioto. Convención Marco de Naciones Unidas sobre el 
Cambio Climático (CMNUCC). New York: Organización de Naciones Unidas; 1998.

15. Coneval. Pobreza urbana y de las zonas metropolitanas en México. México; 2016.

16. Lefebvre H. El derecho a la ciudad. Barcelona: Península; 1969.

17. Programa de Naciones Unidas para el Medio Ambiente. Cambio Climático 2007. Ginebra: Informe de Síntesis del IPCC (Cuarto Reporte Anual); 2008.

18. Daly H. Ensayos hacia una economía de estado estacionario. México Economía, ecología y ética, FCE; 1989.

19. Organization for economic cooperation and development. Cities and climate change. OECD publishing. 2010.

20. Graizbord B, F Montero. Ciudades sostenibles en un mundo cambiante. México: El Colegio de México; 2011.

21. Callicot J. En búsqueda de una ética ambiental. In: Kwiatkowska Teresa, Jorge Issa, editors. Los caminos de la ética ambiental, México: Conacyt/Paza y Valdés/UAM; 1997. p. 85-161.

22. Klein N. Esto lo cambia todo. El capitalismo contra el clima. México: Paidós; 2015.

23. Knutti H. The equilibrium sensivity of the earth to radiation changes Nature Geoscience. 2008;1(11):325-345.

24. Roe G, M Baker. Why is climate sensitivity so impredictable. Science. 2007;318(5850):629-632.

25. Pérez J. Reestructuración y nuevas centralidades en la ZMCM. México CIIEMAD-IPN; 2006.

26. Acuerdos de Cancun. COP 16 2010. fecha de consulta 15 de junio de 2015.
27. Acuerdo de París. COP 21 fecha de consulta 10 de abril, de 2018. 2015

28. Goodland M. Ciencias sociales espacialmente integradas: la tendencia de economía, sociedad y territorio. Economía, Sociedad y Territorio. 2016;16(50):1-20.

29. Bookchin M. Los límites de la ciudad. Madrid: Blume; 1978.

30. Berger A. Milankovitch astronomical theory of paleoclimates: a modern review. Vistas in Astronomy vol 24, New York; 1980. p. 103-122.

31. Constitución Política de los Estados Unidos Mexicanos. México: Porrúa; 2007.

32. Intergovernmental Panel on Climate Change. Summary for policy makers. Climate Change 2007: Synthesis report, Fourth Assessment Report of the Intergovernmental Panel on Climate Change, Cambridge UK. Cambridge, UK: Cambridge University Press; 2007.

33. Instituto Nacional de Estadística y Geografia. México: 2013.

34. Lovelock J. La venganza de la tierra. Madrid: Planeta; 2007.

35. Organización de Naciones Unidas, Las ciudades y el cambio climático. Orientaciones para políticas. Programa de las Naciones Unidas para los asentamientos humanos.

36. Strong M. Secretario General de la Cumbre de Río. La batalla por la sustentabilidad se ganará o perderá. Paris; 1993.

37. Wells J, K Krellenberg. Las vulnerabilidades frente al cambio climático en la Región metropolotanja de Santiago. Eure. 2016;42(125).

38. Wójtowicz M. Crecimiento demográfico y desarrollo socioeconómico en la megalópolis brasileña a principios del siglo XXI. Varsovia: Uniwersytet Warszawsky, Facultad de Geografía y Estudios Regionales; 2017. 